\title{
LA EVOLUCIÓN DEL NEGRINISMO EN EL EXILIO REPUBLICANO EN MÉXICO
}

\author{
JORGE DE HOYOS PUENTE \\ Universidad Nacional de Educación a Distancia \\ dehoyosjorge@gmail.com
}

(Recepción: 27/04/2015; Revisión: 27/10/2015; Aceptación: 09/12/2015; Publicación: 02/12/2016)

1. INTRODUCCIÓN.-2. LA FORMACIÓN Y COMPOSICIÓN DEL NEGRINISMO.-3. LA EVOLUCIÓN DEL NEGRINISMO EN MÉXICO.-4. El NEGRINISMO FUERA DEL GOBIERNO.5. CONCLUSIONES.-6. BiBLIOGRAFÍA

\begin{abstract}
RESUMEN
Este artículo estudia la formación y la evolución del negrinismo en el exilio republicano en México. Tras la derrota republicana en 1939, un sector importante de los vencidos procedentes de todos los partidos políticos, encontraron en la figura de Juan Negrín un referente y una esperanza. Asociada a su figura y a la defensa de la legalidad republicana, sus partidarios articularon una red política transversal, en la que participaron exiliados socialistas y de otros partidos políticos. En este trabajo estudiamos las principales contribuciones de este grupo en el exilio mexicano, trataremos de analizar la composición del grupo, así como sus diferencias con el líder, Juan Negrín, en torno a la estrategia política y los modos de relacionarse con otros grupos del exilio.
\end{abstract}

Palabras clave: exilio; republicano; Negrín; negrinismo; México.

\section{THE “NEGRINISMO” EVOLUTION \\ IN THE REPUBLICAN EXILE IN MEXICO}

\begin{abstract}
This paper analyses the organization and the evolution of the so called "negrinismo" in the Spanish Republican exile in Mexico. After the 1939 Republican defeat, the
\end{abstract}


leading figure of Juan Negrin was seen as an example and a hope by a quiet an important sector of the defeated ones coming from all the political spectrum. Juan Negrin supporters assembled a cross-wise political network related to his leading figure and to the Republican legality defence. Exiled from the Socialist and other political parties took part in this network. This paper focus on this group main contributions in the Mexican exile and it also analyses the group composition, as well as the controversy created between the group and its leader, Juan Negrin, regarding the political strategy and the relationship with other exiled groups.

Keywords: exile; republican; Negrín; negrinismo; Mexico.

$* \quad * \quad *$

\section{INTRODUCCIÓN}

La derrota republicana de 1939 y la represión franquista obligaron a que los núcleos políticos más importantes de la izquierda española desarrollasen su actividad en el exilio. Fuera de España muchas de las normas de funcionamiento existentes se quebraron, dando lugar a un clima profundamente enrarecido, marcado por las circunstancias que rodearon el final de la Guerra Civil española (1). La fractura de las organizaciones políticas que defendieron la legalidad republicana es un hecho contrastado por la historiografía (2). La interpretación de las responsabilidades por la derrota, así como la dispersión geográfica, contribuyó a la ruptura de la unidad de acción dentro de los partidos y sindicatos. Esta situación se dio especialmente en el seno del Partido Socialista Obrero Español, profundamente dividido ya en el interior de España. Con el cuestionamiento de la figura de Negrín al frente del Gobierno por amplios sectores del partido, se inauguró una etapa diferente que cambió los equilibrios internos y los modos de relacionarse de los socialistas con el resto de organizaciones con las que compartieron exilio. En aquellos primeros momentos del exilio surgió el «negrinismo» como una nueva categoría política, que se convirtió en un elemento central con un importante recorrido.

Lo primero que debemos plantearnos es ¿qué fue el negrinismo? Desde luego no parece que podamos estudiarlo dentro del marco de las diversas teorías de las culturas políticas, en la medida en que su composición heterogénea marcó toda su existencia y su duración fue limitada en el tiempo. Lo cierto es que, aunque el principal aglutinante fue la figura de Negrín, y sobre todo la causa legitimista que defendió en el exilio, todos los que participaron de esta posición compartían un mismo relato de lo ocurrido y una estrategia común de futuro,

(1) BAHAMONDE (2014); Alía Miranda (2015).

(2) Heine (1983); Viñas y HeRnÁndez SÁnCHEZ (2009); Hoyos PuENTE (2012). 
aunque las metas finales podían ser muy diferentes. A lo largo de los años del exilio, ser negrinista o antinegrinista se convirtió en un símbolo de identidad para los exiliados más politizados, por encima de algunas otras consideraciones partidistas. Una identidad compleja, que se superponía a otras lógicas propias de las culturas políticas.

A lo largo de las siguientes páginas, trataremos de analizar el negrinismo como una red tejida en el exilio sobre diversos principios. En primer lugar los ya mencionados, la existencia de un relato común de la experiencia vivida y una estrategia común de futuro. En segundo lugar la confianza en el dirigente y sus capacidades. Negrín fue un aglutinante para personas de muy diversa procedencia ideológica porque fue capaz de construir un alto nivel de fidelidades, basadas en la firme convicción de que él era el único hombre capaz de realizar la función de «hombre-puente», imprescindible para subvertir la situación creada por la derrota republicana y la salida de España. La confianza en sus redes e influencias internacionales tal vez fueron sobredimensionadas por sus partidarios, que necesitaban visualizar a la desesperada un salvavidas en medio de las turbulentas aguas del exilio.

\section{LA FORMACIÓN Y COMPOSICIÓN DEL NEGRINISMO}

En los últimos años la figura de Juan Negrín ha sido rehabilitada, al menos parcialmente, por el trabajo riguroso de los historiadores (3). La restitución de la militancia en el PSOE en 2009 y, sobre todo, la creación de la Fundación Juan Negrín en Las Palmas de Gran Canaria, han permitido completar la recuperación social de «la biografía más calumniada de la historia reciente de España», atinado subtítulo de la monografía realizada por Enrique Moradiellos y publicada en 2006. Sin embargo, creo que conocemos mucho menos el grupo heterogéneo que formaron sus partidarios en el exilio y que genéricamente han sido denominados «negrinistas». Son muchos los problemas a la hora de establecer quiénes y cuántos fueron, ante la falta de una organización estable que los aglutinase y sobre todo la ausencia de fuentes. No es fácil fijar, de forma precisa, cuándo comienza a existir el negrinismo como tal, ni si el núcleo original debe situarse en el entorno socialista o trasciende de este. Sin embargo, bien se puede afirmar que el negrinismo estuvo compuesto por dos sectores bien diferenciados; por un lado, sus partidarios dentro del PSOE y por otro, los apoyos externos que fue sumando como resultado de su acción de Gobierno.

Juan Negrín consiguió reunir, durante su gestión en el gobierno, un grupo de socialistas que provenían de todos los sectores del PSOE. Un partido que arrastraba una profunda división interna, derivada de la difícil cohabitación de

(3) Tuñón de lara, Miralles y Díaz Chico (1996); Miralles (2003); Moradiellos (2006); JACKSON (2008). 
concepciones políticas dispares, surgidas de la formación heterogénea de sus militantes y dirigentes (4). La gestión de Negrín al frente del poder ejecutivo en circunstancias y contextos tan complejos, causó un proceso de confluencia en su contra dentro del PSOE de sectores hasta el momento opuestos. El crecimiento exponencial del Partido Comunista de España durante el conflicto, la salida de Indalecio Prieto del Ministerio de Defensa en abril de 1938, la derrota en la batalla del Ebro en noviembre del mismo año, la caída de Cataluña en enero de 1939 y sobre todo el golpe de Estado de Casado en marzo, apoyado por importantes sectores del PSOE, no hicieron sino fracturar de forma irreversible la vida del partido (5). Así, por ejemplo, Luis Araquistain, Indalecio Prieto y Juan Negrín, que habían sido íntimos compañeros, se convirtieron en enemigos acérrimos en los años que vivieron en el exilio, incapaces de superar sus discrepancias en torno al final de Guerra y las estrategias de futuro. El propio Araquistain, con su habitual vehemencia, calificó a Negrín como el peor presidente de la historia de España (6). Sin duda, la ruptura entre Prieto y Negrín marcó de forma decisiva los años del exilio socialista.

Es bien conocida la confluencia contra Negrín de dos tendencias del PSOE que hasta el momento no habían coincidido en casi nada. Por un lado, sectores provenientes del obrerismo largocaballerista, que consideraban a Negrín responsable del crecimiento del PCE y por otro lado, los centristas afines a Prieto, que interpretaban la gestión de Negrín como una abierta traición a su líder, y que también veían como un erróneo empecinamiento su afán por resistir, en unos momentos en que una buena parte de los dirigentes socialistas daban por perdida la guerra y querían acabarla cuanto antes. Unos y otros participaban de universos políticos diferenciados que, sin embargo, encontraron en la crítica a la gestión de Negrín un punto de unión sobre el que volcar todas las frustraciones y prejuicios (7).

Uno de los primeros elementos que debemos tener en cuenta es la diferencia existente entre Juan Negrín y lo que se ha conocido como el negrinismo socialista en el exilio. Por ejemplo, si Negrín era un afiliado socialista moderado, partidario del reformismo social, defensor a ultranza de la legalidad republicana, amigo del orden antes que de la revolución, en el negrinismo militaron protagonistas de la revolución de Asturias, como Ramón González Peña. Para Negrín, la insurrección de octubre de 1934 representaba uno de los errores más graves cometidos por el partido socialista, en la medida en que esa acción revolucionaria suponía un cuestionamiento del orden legal establecido. También son conocidas sus reticencias a entrar en el Gobierno presidido por Largo Caballero, debido a la negativa imagen internacional que, a su juicio, generaba la

(4) GillesPie (1991); HeYwood (1993); Juliá (1997); GraHAM (2005).

(5) Domínguez Aragonés (1940).

(6) FuENTES (2002).

(7) ViñAs y HERnÁNDEZ (2009). 
composición del mismo proyectada por su actitud excesivamente radical (8). Otro de los negrinistas más relevantes a la hora de dirigir la identidad ideológica del grupo, fue el tipógrafo Ramón Lamoneda, que había realizado un viaje, de ida y vuelta, de las filas del PSOE a las del PCE y de nuevo al partido fundado por Pablo Iglesias. González Peña y Lamoneda, quienes junto con Julio Álvarez del Vayo dieron forma al discurso negrinista dentro del PSOE, tuvieron un marcado componente obrerista, incluso revolucionario, como veremos más adelante.

Por tanto, los principales colaboradores de Negrín dentro del PSOE distaron mucho de ser cercanos ideológicamente a las tesis del doctor canario. Fue más bien la confluencia de sus opositores dentro del partido, los antinegrinistas, bien definidos desde mediados de 1938, lo que acabó dando origen a la existencia, por oposición, de los negrinistas socialistas. Así, un hombre procedente del sector centrista del partido, contó con una facción nueva que tomaba su nombre, alterando de forma sustancial la estructura socialista, compuesta en su mayoría por militantes ajenos a su concepción de la política y del socialismo, mucho más cercano al reformismo que a los discursos revolucionarios o marxistas. Desde el principio se fue articulando una cierta distancia discursiva entre el líder y sus seguidores dentro del PSOE. Salvo con los más cercanos, Álvarez del Vayo y Lamoneda, Negrín parece que estuvo más unido a personalidades ajenas al PSOE como Pablo de Azcárate, Francisco Méndez Aspe, José Puche o Antonio Velao. Sin tener en cuenta esta particularidad, difícilmente podemos comprender lo que fue el negrinismo, las diferencias discursivas existentes entre el líder y sus partidarios, sobre todo, dentro del partido socialista.

La ruptura del partido socialista, escenificada en el enfrentamiento PrietoNegrín en torno a la legitimidad del Gobierno y la viabilidad de las instituciones en el exilio, arrastró e impregnó toda la vida política del exilio, durante cuarenta años. Sin embargo, no podemos olvidar que al finalizar la guerra en abril de 1939, Negrín contaba con el respaldo de los más importantes miembros de la Ejecutiva socialista, como su presidente, el dirigente asturiano Ramón González Peña, ministro de sus gobiernos y el secretario general del PSOE, el tipógrafo Ramón Lamoneda. También de la UGT con su secretario general José Rodríguez Vega y figuras de gran relevancia en el sindicato como Amaro del Rosal (9). A pesar del respaldo conseguido en la reunión de las Cortes en Figueras en febrero de 1939, con el golpe de Casado y la derrota llegó la demonización y deslegitimación de su ejercicio, tanto en el partido como en el Gobierno. No podemos perder de vista un hecho crucial: que el ejercicio de la política fue radicalmente diferente en el exilio que dentro del país. La vulnerabilidad aumentó en la medida en que la extraterritorialidad hizo de la política una actividad, con escaso poder real a la hora de ejercer las prerrogativas propias de los

(8) ZugaZagoitia (1977): 164-165.

(9) MAteos (2002). 
cargos. Así, diferentes grupos del PSOE pudieron arrogarse la representación del partido, quedando éste dividido hasta la reorganización realizada en agosto de 1944 en el I Congreso en el exilio, que impuso en la secretaría general a Rodolfo Llopis y la preeminencia de su ejecutiva en Toulouse (10).

La disputa en México por la gestión del contenido del yate Vita marcó en gran medida la quiebra definitiva entre Prieto y Negrín solo días después de finalizada la guerra. Esos recursos, procedentes del Estado español, se convirtieron en un instrumento de suma importancia a la hora de desequilibrar la balanza política. Prieto, al contar con esa baza inesperada a su disposición, realizó dos operaciones simultáneas para acabar con el liderazgo de su antiguo amigo. En primer lugar logró la desestabilización de su Gobierno en el exilio, por medio de las maniobras en la Diputación Permanente de las Cortes, reunidas en julio en París. En segundo lugar, el desplazamiento de sus partidarios en la Ejecutiva del PSOE (11). En ese sentido, la presencia de Prieto en México ayudó a desempeñar esta doble tarea de zapa. A su regreso de París, tras conseguir que la Diputación Permanente declarase inexistente el Gobierno en el exilio y legitimase su control de los fondos del Vita mediante la creación de la JARE, Prieto comenzó a trabajar con sus colaboradores más cercanos en la constitución del Círculo Pablo Iglesias, fundado el 3 de marzo de 1940. Para ello contaba con el reconocimiento de la Ejecutiva Socialista controlada por Lamoneda, que le había designado, junto con Manuel Albar y Lucio Martínez Gil, delegados del PSOE en México (12).

Especial importancia tienen los sucesos acontecidos en septiembre de 1940, que dieron origen al cisma socialista en el exilio. A la llegada de Ramón González Peña y Ramón Lamoneda a México fueron instados por los prietistas Alejandro Otero, Manuel Albar y Lucio Martínez Gil a dialogar sobre la vida del partido y la posible disolución de la Ejecutiva que éstos presidían, lo cual originó notables desencuentros, aireados a través del Boletín de Información para Emigrados Socialistas Españoles (13). Para disgusto de los dos recién llegados, la delegación socialista se arrogaba el título de Comisión Ejecutiva del Partido Socialista, lo que era una suplantación en toda regla de sus funciones (14).

La ruptura del Partido Socialista quedó escenificada con la duplicación de los espacios de sociabilidad. Pese a su pretendido afán integrador, el Círculo Pablo

(10) SiRVENT GarRiga (2014).

(11) Informe de Indalecio Prieto a la Diputación Permanente de las Cortes, México 12 abril 1939. Ateneo Español de México (en adelante AEM), Archivo Tomás Bilbao, Caja 2, Escritos personales y textos políticos 11, hojas 13-22.

(12) PÉREZ Guerrero (2008): 194.

(13) «El Partido Socialista y la Comisión Ejecutiva, una invitación una negativa y unos acuerdos», Boletín de Información para Emigrados Socialistas Españoles, (México) nº 7, 28 de noviembre de 1940 , pp. 6 y 7.

(14) Documento de Ramón Lamoneda: «Situación política del socialismo español a su llegada a México», Fundación Pablo Iglesias (en adelante FPI), Archivo Ramón Lamoneda Fernández (en adelante ARLF)-167-4. 
Iglesias se convirtió en un lugar predominantemente prietista, donde no faltó la representación de un sector del caballerismo. Las bases ideológicas dentro del Círculo Pablo Iglesias se definieron en el anticomunismo, el rechazo a la gestión de Negrín y a toda colaboración política con sus partidarios. Desde la experiencia de la Guerra y el Frente Popular, ese socialismo moderado transitó hacia una apuesta decidida por la democracia liberal y la extensión de derechos individuales desde un reformismo político y económico. La tesis de Prieto condenando el obrerismo revolucionario como estrategia de actuación preferente del partido y el sindicato, fue conformando su apuesta por un modo de actuar más moderado dentro del sistema parlamentario, respetando siempre las reglas de juego y evitando cualquier episodio como el de la Revolución de Asturias (15).

Tanto el control financiero, como la ausencia de México de Negrín, contribuyeron a fortalecer las tesis de Prieto en el partido socialista. El hecho de que los delegados del partido en México decidiesen suplantar a la Ejecutiva salida de España, dirigida por González Peña y Lamoneda, desencadenó la ruptura total. Estos no aceptaron aquella decisión y, al intentar ingresar en el Círculo Pablo Iglesias, fueron vetados. A partir de entonces, los socialistas negrinistas tardaron demasiado tiempo en organizarse políticamente en México, perdiendo un tiempo precioso. Así el Círculo Cultural Jaime Vera nació el 21 de diciembre de 1941, donde se organizaron los partidarios de la legalidad del partido que apoyaban las tesis y la actuación de Juan Negrín (16). Allí militaron, además de González Peña y Lamoneda, socialistas distinguidos como Max Aub, Matilde de la Torre, Edmundo Lorenzo, Juan Simeón Vidarte, Vicente Sarmiento, Ángel Galarza, Matilde Cantos y tantos otros. De esta manera se consumaba la existencia de dos estructuras del PSOE en México, dos espacios de sociabilidad contrapuestos, con discursos bien diferenciados. En enero de 1942 nacía El Socialista, como órgano de expresión del Círculo Jaime Vera, dirigido por Fernando Vázquez Ocaña (17). A través de su publicación podemos ver cómo la configuración ideológica de sus principales protagonistas se articuló en torno a un reconocimiento de la herencia marxista dentro del PSOE (18). Entre las señas de identidad del discurso negrinista del Jaime Vera estuvo la defensa de la legitimidad de la revolución de 1934, la defensa del Frente Popular como mecanismo de lucha obrera y los llamados a la colaboración constante con otras organizaciones obreras hermanas. Con este discurso no sorprende que, según la información que proporciona Abdón Mateos, la UGT negrinista fue mayoritaria en América con alrededor de 2. 000 afiliados (19). Una visión opuesta a la vía reformista, anticomunista y antinegrinista que se venía formulando en el círculo prietista.

(15) PRIETO (1942).

(16) PÉrez Guerrero (2008): 196.

(17) FPI, Sección Publicaciones Periódicas Sig. 2826.

(18) «La vuelta a Marx. Reivindicación de Marx y de su interpretación de la historia», $E l$ Socialista (México), n. ${ }^{\circ}$ 8, agosto de 1942, p. 2.

(19) Mateos (2002): 23. 
A pesar de que Negrín no compartía las tesis obreristas y marxistas de sus partidarios, el presidente del Consejo de Ministros necesitaba de su apoyo para mantener sus opciones legitimistas, pero en ningún caso se puede afirmar que la base del discurso negrinista en México fuese fiel a las coordenadas ideológicas del político canario. Si México fue el lugar donde se desencadenó la ruptura total, el eje del discurso socialista negrinista giró en torno a dos figuras claves, Ramón Lamoneda afincado en México y Julio Álvarez del Vayo, residente en New York. Ante la imposibilidad de actuar del propio Negrín, exiliado en Londres desde la caída de París, estos dos dirigentes socialistas articularon el discurso socialista sobre la premisa de la continuidad del Gobierno republicano en el exilio (20). La afirmación de una concepción obrerista, sindical, marxista e inequívocamente republicana fueron las bases sobre las que se construyó la imagen del socialismo dirigido por Ramón Lamoneda (21).

El segundo gran núcleo de apoyos que consiguió recabar Negrín tenía una procedencia todavía más heterogénea. Negrín contó con el respaldo de la mayoría de los ministros de su Gobierno en los difíciles momentos del final de la Guerra en el invierno de 1939, dispuestos a trasladarse con él a continuar luchando en la zona centro del país tras la caída de Cataluña (22). Provenientes de fuerzas políticas tan dispares como Izquierda Republicana, PSOE, PCE, CNT o ANV, se convirtieron en el exilio en un puntal fundamental en la defensa de las tesis formuladas por Negrín. A pesar de no tener una militancia compartida, estos ministros mostraron una fuerte coincidencia con su política y una lealtad sobresaliente durante el exilio. Este núcleo se convirtió en el interlocutor preferente del médico canario, junto con sus colaboradores más fieles, entre los que destacaron José Puche, Rafael Méndez y Pablo de Azcárate (23). Los puntos de acción fueron tres. En primer lugar, la defensa de la labor realizada por el Gobierno y su política de resistencia, frente a las tesis derrotistas de sus detractores. En segundo lugar, la firme convicción de la continuidad de la legalidad republicana, emanada de la voluntad popular y de la Constitución de 1931, amparadas en el acuerdo de las Cortes en Figueras en febrero de 1939, hecho que no había de modificarse por la dimisión del presidente Azaña. En tercer lugar, la necesidad de restablecer la unidad de acción de los exiliados en torno al Gobierno, como mecanismo de interlocución válido con las potencias democráticas y la Unión Soviética.

La implicación de sus ministros en la defensa de la gestión del Gobierno y especialmente de la figura de Negrín, estuvo presente desde el primer momento, ante la creciente espiral de críticas surgidas en el exilio, potenciadas por la con-

(20) Alpert (1990): 73-90.

(21) LAMONEDA (1942).

(22) Carta de Tomás Bilbao, Segundo Blanco, Bernardo Giner de los Ríos, Paulino Gómez Saiz, Ramón González Peña, José Moix y Antonio Velao a Juan Negrín, (7 febrero 1939). AEM, A. Tomás Bilbao, Caja 2, Escritos personales y textos políticos 11: 11-12.

(23) AzCÁrate (2010). 
trovertida decisión de la Diputación Permanente de desconocer su Gobierno en julio de 1939 (24). Así, por ejemplo, Tomás Bilbao confrontaba al socialista Trifón Gómez por las acusaciones que vertía sobre la mala gestión del Gobierno republicano, y defendía la tesis de que aquella espiral de calumnias solo beneficiaba a los franquistas (25). Cuando en marzo de 1940 el lehendakari José Antonio Aguirre presionaba a Acción Nacionalista Vasca para que Tomás Bilbao dejase de ser ministro en el Gobierno de Negrín porque, a su juicio, perjudicaba los intereses de Euskadi, este defendía que Negrín estaba realizando importantes contactos discretos con los principales líderes internacionales y que solo Negrín era el hombre capaz de llevarlos de regreso a España y a Euskadi (26).

Uno de los asuntos que más preocupó desde el principio a este núcleo de colaboradores fue la actitud silenciosa de Negrín ante los más diversos asuntos surgidos en el exilio. Tomás Bilbao solicitaba a Negrín que hiciese una declaración en contra del pacto germano-soviético, una oportunidad única para desembarazarse del sambenito de «comunistas» con que eran demonizados por sus críticos, a lo cual Negrín se opuso cauteloso (27). Este exceso de reserva de Negrín desesperó en no pocas ocasiones a sus partidarios, hecho que se agravó con el traslado a Londres, donde Negrín estuvo muy limitado por las restricciones que le impusieron las autoridades británicas. Negrín consideraba importante su presencia en Londres, donde se encontraban exiliados los representantes de otros gobiernos europeos desplazados por el nazifascismo. Sin embargo, la lucha política interna del exilio se libraba en México. A pesar de la pluralidad ideológica de este núcleo y algunas de las importantes desafecciones, surgidas por el sentimiento de abandono que experimentaron tras la salida de Negrín hacia Londres, este grupo fue muy cercano al presidente del Gobierno en el exilio.

Por último, conviene señalar que, a pesar de lo sostenido por sus detractores, el PCE no formó parte del negrinismo en el exilio. Al menos no de una forma sostenida en el tiempo. Como ya mostrara Hartmut Heine en los años ochenta, el PCE siguió su propia estrategia política en la década de los cuarenta, apoyando las tesis negrinistas de forma coyuntural, siempre y cuando el contexto internacional demandara estar cerca de esas posiciones (28).

(24) «Acuerdo de la Diputación Permanente de las Cortes» (París, 26 de julio de 1939). Copia en AEM, A. Tomás Bilbao, caja 2, escritos personales y textos políticos 11: 33.

(25) Carta de Tomás Bilbao a Trifón Gómez (París, 28 de agosto de 1939), AEM, A. Tomás Bilbao, Correspondencia 15: 6.

(26) Carta de Tomás Bilbao a la dirección de ANV (marzo, 1940), AEM, A. Tomás Bilbao, Caja 3, Escritos personales y textos políticos 6: 5-13.

(27) Telegramas de Tomás Bilbao a Juan Negrín (25 de agosto de 1939) y contestación de este al día siguiente y réplica de Tomás Bilbao del día 27 en AEM, A. Tomás Bilbao, Caja 1, Correspondencia 16: 41 y 42.

(28) HEINE (1983). 


\section{LA EVOLUCIÓN DEL NEGRINISMO EN MÉXICO}

México se convirtió en el centro neurálgico de la actividad política del exilio, tanto por la masiva presencia de dirigentes republicanos de todos los partidos y organizaciones, como por la tolerancia de las autoridades del país. La dimisión de Azaña y la negativa de Martínez Barrio a sustituirlo por un lado, y el desconocimiento de la Diputación Permanente del Gobierno Negrín por otro, dejaron desdibujada la representación de las instituciones republicanas, a pesar de la negativa de este y sus partidarios a acatar esta última decisión. Sin relaciones diplomáticas formales con el Gobierno mexicano, los primeros años estuvieron marcados por la provisionalidad, la incertidumbre y, hasta cierto punto, el caos, derivado de la gestión económica de los fondos llegados en el Vita, procedentes, en última instancia, del Estado español (29). La duplicación de las organizaciones de ayuda y el profundo enconamiento de las disputas políticas generaron más tensiones entre el colectivo exiliado, provocando no pocas desafecciones y aumentando la frustración de la derrota. Como ya apuntamos, el negrinismo en México comenzó a organizarse a finales de 1941, animado por las noticias internacionales y la mundialización de la Guerra con la entrada de Estados Unidos y la Unión Soviética en el conflicto. Era una fecha tardía, en la medida en que el entorno de Indalecio Prieto ya había realizado un importante trabajo de captación política y de suplantación de las funciones del PSOE. A diferencia de Prieto, que organizó su sector del partido simultáneamente a la puesta en funcionamiento de la JARE, el negrinismo se articuló políticamente cuando los fondos del SERE en México, controlado por los negrinistas y gestionado por el CTARE, ya se habían prácticamente extinguido, mermando su capacidad para establecer clientelas (30).

Otro factor determinante en la desigualdad de fuerzas estaba en la distancia y el silencio de Negrín. Contadas fueron las intervenciones públicas de Negrín en aquellos tiempos de exilio en Londres. Por ello, su discurso en la conmemoración del 19 de julio, fecha emblemática de la reacción del pueblo español en armas frente a los golpistas, celebrado en 1941 en el Hogar Español, alcanzó una gran resonancia en América, difundido como folleto (31). Allí trató Negrín de justificar su silencio en la prudencia que debía mantener en aquel complejo escenario internacional, donde la falsa neutralidad del franquismo, era un estorbo a la consecución de los objetivos de conseguir la unidad nacional en apoyo a las potencias aliadas. Negrín demandó la necesaria unidad de los españoles para situarse al lado de Churchill, Roosevelt y Stalin frente a Franco, Hitler y Mussolini. Recordando aquella efeméride pretendió rendir homenaje al levan-

(29) Herrerín (2007); Mateos (2009); VeláZquez (2014).

(30) A pesar del agotamiento de fondos, el doctor José Puche puso a disposición de la Unión Democrática Española 14.500 pesos mexicanos. «Resumen General de Estado de Cuentas de Unión Democrática Española desde su constitución hasta junio de 1943, fecha en que se disuelve dicho organismo» AEM, 43. 415. folios 1-6.

(31) NegRín (1941): 9-18. 
tamiento popular que en 1936 salvó a la República, frente a la sublevación facciosa y la injerencia extranjera.

Su discípulo y amigo, José Puche, le hacía saber, en diciembre de 1941, la necesidad de una mayor implicación pública como presidente del Gobierno, manifestando su adhesión con los países democráticos en guerra. Puche le argumentaba que su mutismo desorientaba a muchos exiliados en México, deseosos de escuchar a su presidente (32). A pesar de su silencio público, Negrín no desistió de explicar a sus más allegados sus decisiones, aunque no siempre se consideraban acertadas. En este caso, Negrín justificaba su discreción por un sentido de responsabilidad que debía no prodigarse con declaraciones efectistas que pudieran dificultar los planes de futuro. Negrín confiaba en las gestiones veladas que, tanto él como Álvarez del Vayo desarrollaban en Gran Bretaña y Estados Unidos (33). Sin duda, Negrín era consciente de que la batalla política más decisiva no se iba a producir en México, donde se encontraba buena parte del exilio más politizado, pero también el más dividido. Negrín y sus colaboradores en Londres creían en la necesidad de establecer un frente único, que dejase atrás las discrepancias. Esa situación vendría dada cuando sus gestiones discretas diesen fruto. Esta opinión, a finales de 1941, mostraba su altura de miras, pero también su desconocimiento del clima de crispación que existía en México, alimentado por sus adversarios. La mundialización de la guerra europea en 1941 hizo crecer las expectativas positivas de Negrín, que solicitaba, por medio de José Puche, a sus ministros leales en México que le facultasen para tomar decisiones urgentes en el momento preciso (34). Sin especificar su determinación, todo parece indicar que preparaba una declaración de adhesión del Gobierno republicano a la lucha contra el nazifascismo.

La estrategia de los socialistas partidarios de Negrín fue defender la tesis de que el partido no podía modificarse en el exilio, ya que tenía a la mayoría de sus militantes en cárceles y sus agrupaciones disueltas por la represión y que, por tanto, se debía mantener la estructura que se había aprobado en el último congreso en España. Desconocían con ello los cambios introducidos por sus detractores dentro del partido y no reconocían a los diferentes grupos que tanto en el interior como en el exilio, se arrogaban la representación del PSOE. Así, la tarea era construir la unidad del exilio por medio de otros espacios, como la Unión Democrática Española, la UDE, creada el 16 de febrero de 1942 para conmemorar el triunfo del Frente Popular (35).

(32) Telegrama de José Puche a Juan Negrín (México, 10 de diciembre de 1941), AEM, A. Tomás Bilbao, Caja 1, correspondencia 12: 83.

(33) Telegrama de Juan Negrín a José Puche (Londres, 13 diciembre 1941); AEM, A. Tomás Bilbao, Caja 1, correspondencia 12: 38-39.

(34) Telegrama de Juan Negrín a José Puche (Londres, 13 diciembre 1941) y respuesta al día siguiente de Antonio Velao y Ramón González Peña, AEM, A. Tomás Bilbao, Caja 1 Correspondencia 12: 40 y 108 .

(35) «Proyecto de Unión Democrática Española», Fundación Pablo Iglesias, Archivo Ramón Lamoneda Fernández 171-49. 
De la UDE formaron parte el Comité de Unidad de los Republicanos españoles, que aglutinaba a destacados miembros de Izquierda Republicana, como Antonio Velao, Luis Fernández Clérigo y Elfidio Alonso, críticos con la postura beligerante de su organización respecto del Gobierno Negrín; el PSOE y la UGT negrinista, el PCE, el PSUC, y la Unión de Rabassaires (36). Sorprende la cercanía del PCE, después de varios años de alejamiento de Negrín. Sin duda este cambio de estrategia después de la entrada de la Unión Soviética en la Guerra Mundial fue decisivo. Hasta ese momento, para los comunistas españoles la legitimidad del Gobierno Negrín había pasado a segundo plano y la guerra mundial era interpretada como un conflicto imperialista del que los exiliados españoles debían quedar al margen (37).

Velao, diputado de Izquierda Republicana y ministro con Negrín, actuó de presidente de la UDE, Ramón Lamoneda fue su secretario general, el tesorero Antonio Mije y como director de su boletín ejerció Elfidio Díaz. UDE. Órgano central de la Unión Democrática española, nació en julio de 1942 con el fin de dar voz a esta nueva plataforma que reivindicaba la acción conjunta del exilio. En su manifiesto fundacional realizaron un llamamiento pacífico a la acción contra la dictadura, reconociendo al Gobierno de Negrín como único legítimo, junto con los gobiernos autónomos de Cataluña y Euskadi. Situándose al lado de las potencias aliadas que luchaban en la Segunda Guerra Mundial contra el fascismo, apostaban por la movilización y la concienciación como modo de mantener viva la esperanza del pronto regreso, una vez derrotado el fascismo europeo (38).

Durante el periodo en el que la UDE estuvo vigente, Antonio Velao se convirtió en el principal interlocutor de Negrín en México, defendiendo sus tesis en diversos foros, en su calidad de presidente de UDE. Su discurso se basaba en una afirmación de España como el «pueblo cautivo», atacado por las derechas españolas, en alianza con el fascismo internacional, para evitar que se cumpliera su deseo de constituirse en República. Por ello, cualquier intento de entendimiento con los monárquicos, representantes de esa España que oprime al pueblo, fue condenado abiertamente. UDE denunciaba lo que consideraba un atropello a toda lógica, el provocado por Acción Republicana Española, controlada por Martínez Barrio, que reconocía la legalidad republicana de las Cortes a través de la Diputación Permanente, al mismo tiempo que desconocía a su Gobierno. Velao, en su calidad de ministro, recordaba el apoyo al Gobierno Negrín de las Cortes en Figueras, decisión que no podía ser cambiada por una Diputación Permanente, que había sufrido de forma ilegal importantes

(36) HeINE (1983): 107.

(37) Véase «España y la contienda europea», España Popular, n. ${ }^{\circ} 1,18$ de febrero de 1940, p. 5, también el editorial del primer número de Nuestra Bandera, «iUnidad por la Paz! ¡Lucha por el pueblo español! 1 junio 1940, pp. 3 y sig.

(38) «Las bases de la UDE» (México, 10 de febrero de 1942). FPI, Archivo de Amaro del Rosal, 357-3. 
variaciones en su composición. Solo el Gobierno podía representar a la nación en aquellas condiciones, agregaba Velao, e intentar relevarlo mediante artimañas era impropio de demócratas (39).

Por carta, los ministros Tomás Bilbao, Segundo Blanco, Ramón González Peña, José Moix y Antonio Velao explicaban a Negrín los avances alcanzados en torno a la UDE y la necesidad de una mayor implicación del presidente del Gobierno en los asuntos políticos del exilio en México, donde Indalecio Prieto adquiría cada vez más protagonismo, situándose como «gentes de orden» contra el comunismo y contra el Gobierno Negrín (40). Los ataques a la UDE por parte de los seguidores de Indalecio Prieto no tardaron en llegar. Así desde Acción Republicana Española y por medio de un comunicado, se criticaron los intentos por reeditar pactos como el Frente Popular, fijando como principal punto de desencuentro el reconocimiento por parte de UDE del Gobierno presidido por Negrín, que ellos consideran inexistente, en tanto en cuanto así lo había acordado la Diputación Permanente en julio de 1939 (41).

Negrín, desde Londres, alentaba el trabajo de sus ministros, a los que pedía confianza mientras que volvía a justificar su silencio con dos argumentos; que no era momento de desperdiciar fuerzas en conflictos internos del exilio, ni ahondar en las divisiones existentes y por su mermada capacidad de acción política, que debía centrarse en los contactos discretos con los dirigentes internacionales y en alentar el trabajo de los partidos políticos en el interior de España. Su análisis de la situación era que el destino de España estaba unido al resultado de la Guerra mundial y que su capacidad de influencia debía centrarse en la gestión internacional, más que en las luchas de los partidos, tarea que sus ministros estaban desarrollando de forma satisfactoria para alcanzar la unidad en torno a UDE (42). Negrín insistía en la imposibilidad de realizar manifestaciones partidarias desde Londres por sentido institucional y para no restar eficacia a las tareas desarrolladas por sus partidarios, tanto en el interior de España como en el exilio (43). A finales de agosto, Antonio Velao realizaba una declaración pública repitiendo estos argumentos, señalando la continuidad del poder Ejecutivo a pesar de la vacante de la jefatura del Estado, hecho producido al margen de las decisiones del Gobierno y fuera de sus competencias constitucionales para resolver la situación (44).

(39) Velao (1942): FPI, Archivo Amaro del Rosal, AARD-290-3.

(40) Carta de los ministros a Juan Negrín (México 18 de julio de 1942), AEM, A. Tomás Bilbao, Caja 1 Correspondencia 16: 31-32.

(41) «Circular n. ${ }^{\circ} 39$ de la Junta Central de ARE» (México, 30 de julio de 1942), Centro Documental de la Memoria Histórica, Salamanca, fondo Carlos Esplá 5. 2/5118-a.

(42) Telegrama de Juan Negrín a Antonio Velao (Londres, 21 de agosto de 1942), AEM, A. Tomás Bilbao, Caja 1 Correspondencia 12: m25-28.

(43) Mensaje de Juan Negrín a sus ministros (Londres, 26 de agosto 1942), AEM, A. Tomás Bilbao, Caja 1 Correspondencia 12: 41-43.

(44) «Declaración de Antonio Velao» (México, 28 de agosto de 1942), AEM, A. Tomás Bilbao, Caja 1 Correspondencia 12: 105-108. 
Negrín apoyaba desde Londres con discreta satisfacción, los trabajos realizados por la UDE, hecho que podemos comprobar a través de su correspondencia con Antonio Velao (45). La UDE vio frustrados sus trabajos por el cambio de estrategia del PCE, y su apuesta por la Junta Suprema de Unión Nacional, lo que supuso la ruptura en junio de 1943 (46). Puesto que la constitución de las Juntas, ya fuera la JSUN, o la Junta Española de Liberación, asumían en sus discursos la inexistencia del Gobierno Negrín, la UDE entró en crisis y desapareció.

A raíz de la disolución de la UDE a finales de 1943 sus partidarios fuera del PSOE buscaron nuevas posiciones desde las que seguir luchando. Los ministros de Negrín residentes en México realizaron una nueva declaración, mostrando su fe en la victoria de las naciones unidas contra el fascismo, que declaraban como lucha iniciada en España. Este hecho debía llevar aparejado la restauración de la legalidad constitucional en España y sus instituciones, tanto del Gobierno central, como de los gobiernos autónomos de Cataluña y Euskadi. En su enésimo llamamiento a la unidad a mediados de 1943, planteaban la necesidad de construirla en torno al Ejecutivo elegido por los españoles, y no a juntas y órganos formados por partidos y personalidades en el exilio, pero carentes de toda legitimidad institucional (47). El propio Tomás Bilbao alcanzó una importancia singular al asumir la presidencia de la Comisión española de ayuda a la Unión Soviética en México, una plataforma que llegó a albergar en sus filas a figuras tan enfrentadas en aquellos momentos, como Diego Martínez Barrio, Álvaro de Albornoz, Vicente Uribe y muchos otros (48).

También Juan Negrín desde Londres rechazó la política de Juntas, impulsada por el exilio. Tanto la JEL como la JSUN le parecieron erradas al tratar de articular la unidad en torno a ellas, cuando lo único que contaba con cierta viabilidad a la hora de influir en el concierto internacional era el reconocimiento expreso de la existencia de un Gobierno legítimo de España en el exilio (49). Negrín, consciente de que la Junta Española de Liberación había sido ideada expresamente para sustituir su legitimidad, acentuó sus contactos diplomáticos con las potencias aliadas con el fin de reivindicar su papel (50). La conciencia de que ese hecho se produciría pronto, también aceleró el ritmo de los acontecimientos en el exilio y la pugna entre partidarios de distintas salidas. Ante los intentos de la JEL, dirigida por Martínez Barrio e Indalecio Prieto, de convocar

(45) Telegrama de Juan Negrín a Antonio Velao, (Londres, 21 de agosto de 1942). AEM, A. Tomás Bilbao, Caja 1 Correspondencia 12: 25-28.

(46) «Acta del Consejo Directivo de Unión Democrática Española» (México, 5 de junio de 1943). AEM, A. Tomás Bilbao, Caja 2, Escritos personales y textos políticos 11: 50-51.

(47) «Declaración de los ministros de Negrín residentes en México» (México, 26 de mayo de 1943), AEM, A. Tomás Bilbao, Caja 2, Escritos personales y textos políticos 11: 47-49.

(48) AEM, A. Tomás Bilbao, Caja 2, Expediente 7: 4.

(49) ALPERT (1990): 90.

(50) Moradiellos (2006): 533 y sig. 
las Cortes republicanas en México, en septiembre los ministros Tomás Bilbao, Segundo Blanco, Ramón González Peña, José Moix, Vicente Uribe y Antonio Velao escribieron al presidente mexicano Manuel Ávila Camacho, para solicitarle que no autorizase la reunión, argumentando que Martínez Barrio había dimitido de su cargo en 1939, cuando se negó a cumplir el mandato constitucional de asumir la presidencia interina de la República después de la dimisión de Manuel Azaña (51).

En 1944 el ritmo de los acontecimientos aumentó la tensión creciente entre Negrín y sus partidarios en México. Negrín defendía la necesidad de conservar la serenidad frente a los ataques y conservar la calma para dar ejemplo (52), mientras que sus partidarios apostaban por una mayor implicación pública de este, situación que trataban de paliar con manifiestos firmados por ellos como miembros del Gobierno, donde sostenían la vigencia del ejecutivo, la necesidad de reconstruir la unidad de los antifascistas españoles y el alineamiento claro con las potencias aliadas (53). Para tratar de influir en sus decisiones José Puche presionaba también a Francisco Méndez Aspe, colaborador íntimo de Negrín y exiliado en Londres con él, para conseguir una declaración pública (54).

El 11 de septiembre de 1944, Negrín envió un telegrama a Antonio Velao informándole de su intención de trasladarse a México. Su postura no había cambiado: la situación legal en España «solo puede alterarse en el país, bien por el voto o revolucionariamente, creando una nueva situación de hecho, pero en modo alguno en conciliábulos de partido o personajes políticos por muy eminentes que sean». Negrín defendía la legalidad de su Gobierno, a pesar de estar vacante la presidencia de las Cortes, y por haber expirado su mandato ordinario al exceder el tiempo legal de la legislatura. Ante la imposibilidad de su renovación mediante votación libre del pueblo español, estas quedaban prorrogadas automáticamente. Negrín se mostraba poco partidario de reunir las Cortes fuera de España y apostaba por una política del Gobierno discreta. A su juicio y en esas circunstancias, no se podía dar cuenta de ella públicamente en unas Cortes fuera de España, hecho que restaría capacidad de acción. Para Negrín, «Las cuentas se darán cuando se pueda» (55). Sin embargo, ese mismo día, Negrín envió un telegrama a Luis Fernández Clérigo, vicepresidente segundo de las Cortes. En él le solicita que pusiera en marcha el procedimiento para la sustitución del presidente de la

(51) «Carta de los ministros de Negrín al presidente Manuel Ávila Camacho» (México, septiembre 1943), AEM, A. Tomás Bilbao, Caja 1, correspondencia 17: 12-13.

(52) Cablegrama de Juan Negrín a Antonio Velao (Londres, 9 de marzo de 1944), AEM, A. Tomás Bilbao, caja 1, correspondencia 12: 49.

(53) Álvarez Del Vayo, Velao, González Peña, Blanco y Bilbao: «El Gobierno legítimo de la República española examina la situación de España y la emigración republicana». (México, 29 de marzo de 1944). FPI, AARD-307-6.

(54) Telegrama de José Puche a Francisco Méndez Aspe (México, 26 de agosto de 1944), AEM, A. Tomás Bilbao, Caja 1, correspondencia 12: 85.

(55) Telegrama de Juan Negrín a Antonio Velao (Londres, 11 de septiembre de 1944), AEM, A. Tomás Bilbao, Caja 1, Correspondencia 12: 50-51. 
República en funciones y también para reformar el Gobierno ya que, a su juicio, «se encuentra desasistido de los colaboradores necesarios» (56). Sin duda, se tratan de dos mensajes contradictorios, difícilmente compatibles, que muestran de forma clara los problemas existentes dentro del complejo equilibrio en que se movía por entonces la legalidad republicana.

Muchos fueron los enfrentamientos y escaramuzas en ese periodo fundamental marcado por el inicio del fin de la Guerra Mundial, así como los intentos para influir políticamente ante las potencias aliadas. La falta de un proyecto común que aglutinase al exilio republicano azuzó nuevamente los enfrentamientos. A pesar de ello, existió un cierto consenso en la necesidad de reconstruir la unidad en torno a las instituciones republicanas, aunque sin compartir del todo los pasos a seguir. Las prisas de Diego Martínez Barrio por convocar las Cortes en enero de 1945 fueron motivo de nuevo conflicto. Así, Matilde de la Torre, diputada socialista partidaria de Negrín, reprochaba al político sevillano tratar de establecer una dictadura personalista, acumulando cargos y representaciones en unas instituciones a las que tanto había debilitado antes, en clara referencia a su dimisión en abril de 1939 (57).

En un intento por aumentar su influencia y proyectar su legitimidad, los negrinistas organizaron un gran acto político en el Arena México, el 29 de enero de 1945. Bajo el lema «Por la reconquista de España» proclamaron nuevamente la necesidad de recomponer la unidad de acción en torno al Gobierno presidido por Negrín. Entre los oradores estuvieron Ramón Lamoneda, Julio Álvarez del Vayo, Antonio Velao, Vicente Uribe y el subsecretario de gobernación mexicano el licenciado Fernando Casas Alemán (58). El evento también contó con la presencia de Freda Kirchwey, directora de The Nation y pieza clave a través de Julio Álvarez del Vayo en la financiación estadounidense de las actividades negrinistas. En esta ocasión los dos discursos más relevantes fueron los de Vicente Uribe y Antonio Velao. El del primero porque suponía la enésima pirueta en pocos años del PCE respecto a la legitimidad del Gobierno Negrín. En nombre del buró político, Uribe mostraba su adhesión a Negrín y declaraba el reconocimiento de la JSUN del liderazgo del doctor canario, un giro de ciento ochenta grados del PCE, tomado en noviembre de 1944. Velao, por su parte, realizó un análisis de la situación del exilio en su conjunto estableciendo la existencia de dos bloques, uno de derechas y otro de izquierdas que pugnaban por modelos diferentes de república. Velao situaba en el bloque de la derecha a todos los derrotistas y perseguidores de la continuidad de la Segunda República, partidarios, según él, de establecer un régimen más parecido al del

(56) Telegrama de Juan Negrín a Luis Fernández Clérigo (Londres, 11 de septiembre de 1944), AEM, A. Tomás Bilbao, Caja 1, correspondencia 12: 52.

(57) Carta de Matilde de la Torre a Diego Martínez Barrio (Cuernavaca, el 20 de diciembre de 1944) FPI, ARLF, 166-38.

(58) iPor la Reconquista de España!, unidad de lucha, gobierno Negrín, República. Mitin del Arena México, 29 de enero de 1945, folleto. Utilizo el ejemplar del AEM. 
bienio negro que al deseado por el «pueblo». Muy crítico por su intento de juntar a las Cortes, reunidas en el Club France el 10 de enero sin los requisitos constitucionales imprescindibles y con evidentes defectos de forma en la convocatoria de los diputados, Velao sostenía que solo desde la restauración de la legalidad republicana podía respetarse la voluntad popular surgida de las elecciones de febrero de 1936. La postura negrinista quedó clara: era necesario constituir un Gobierno de concentración presidido por Negrín, que tuviese como objetivo derrocar a Franco con ayuda de las potencias aliadas.

Negrín asumió pronto la necesidad de pactar con Martínez Barrio y descartar la opción de mantener en firme su dimisión de 1939. Era necesario anteponer la construcción de una posible mayoría a las rencillas políticas. Tras la convocatoria fallida y totalmente irregular de las Cortes de enero de 1945, Negrín apostaba por evitar ahondar en las escisiones republicanas y buscaba un programa común de acción de Gobierno para no decepcionar a los españoles del exilio y del interior (59). En las comunicaciones con sus partidarios, Negrín mostró un cierto optimismo tras su gira por Francia, antes de llegar a México. Parecía confiado en poder llegar a un acuerdo que le permitiese continuar en el Gobierno tras la reorganización institucional (60). Ya en México, el 8 de agosto de 1945, Negrín convocó a una reunión con todos los partidos políticos, sin exclusiones, a la que asistieron todos los grupos, salvo el PSOE prietista. En aquella reunión, para desatascar la situación se acordó la solicitud a Diego Martínez Barrio de convocatoria a Cortes (61).

En agosto, días antes de la reunión definitiva de las Cortes, en un intento por evitar la colisión entre socialistas, los distintos grupos del PSOE en México se reunieron para tratar de superar las divisiones. Además del Círculo Pablo Iglesias y el Círculo Jaime Vera, también se dieron cita las Agrupaciones Regionales Socialistas, compuestas por una parte importante de los fieles a Largo Caballero, y el Comité Central de los Socialistas de Euskadi. La reunión, permitió un acercamiento de los caballeristas y los vascos al grupo mayoritario liderado por Prieto, pero no fue así para el caso de los negrinistas (62). Fue entonces cuando se disolvió el Círculo Pablo Iglesias para constituir a continuación la Agrupación Socialista de México (63). Los socialistas en México trataban de cumplir así el llamado a la unidad de acción que provenía de la Ejecutiva

(59) Telegrama de Juan Negrín a Antonio Velao (Londres, 20 de enero de 1945), AEM, A. Tomás Bilbao, Caja 1, correspondencia 12: 53.

(60) Telegrama de Juan Negrín a Antonio Velao (París, 9 de febrero de 1945), AEM, A. Tomás Bilbao, caja 1, correspondencia 12: 54.

(61) «Nota informativa de la Agencia España» (México, 8 de agosto de 1945), AEM, A. Tomás Bilbao, Caja 2, documentos personales 8: 4.

(62) «Acta de la reunión celebrada el 16 de agosto de 1945». FPI, A. de Mariano Moreno Mateo, AMMM 474-2.

(63) «Reglamento de funcionamiento de la Agrupación Socialista de México», FPI, A. de Enrique de Francisco. AEFG-158-12. 
de Toulouse, surgida del I Congreso en el exilio, celebrado en agosto de 1944. El Círculo Cultural Jaime Vera, se negó a disolverse e integrarse en la Agrupación basándose en un argumento de que las estructuras del partido socialista no podían cambiarse en el exilio y negando el reconocimiento a las decisiones de dicho Congreso (64). Así se mantuvo el cisma más importante entre los socialistas.

La reunión de Cortes representó la «normalizaron» de las relaciones institucionales, con la asunción de Diego Martínez Barrio de la presidencia de la República en funciones y la sustitución, para sorpresa de muchos, de Negrín por José Giral en la presidencia del Gobierno en el exilio. La posición de Negrín y sus partidarios en las Cortes fue nítida. Incluir en el Ejecutivo a todos los partidos y sindicatos sin exclusiones, sumar a las personalidades relevantes que aceptaran la Constitución y formar un Gobierno fuerte, capaz de influir internacionalmente (65). Este fue el programa que se aprobó, pero sin Juan Negrín y sus partidarios al frente, sino con la figura conciliadora de José Giral. Los negrinistas asumieron con respeto institucional el cambio y a pesar de no compartirlo, mostraron públicamente su apoyo al Gobierno surgido entonces (66).

\section{EL NEGRINISMO FUERA DEL GOBIERNO}

Desde fuera del Gobierno Giral, los negrinistas apoyaron sin reservas su legitimidad y defendieron su continuidad en los momentos de incertidumbre. Así, tras la reunión de las Cortes los días 7, 8 y 9 de noviembre de 1945, destinada a la aprobación del programa de acción del Gobierno, y donde Indalecio Prieto llamó a la salida plebiscitaria superadora de la legalidad republicana, los negrinistas organizaron un acto en el teatro de los Cinematografistas el día 25 de ese mes, para denunciar los intentos por acabar con la República (67). Un acto en el que solo participaron socialistas negrinistas, como José Rodríguez Vega, Ángel Galarza, Julio Álvarez del Vayo, Ramón Lamoneda y el propio Juan Negrín. En sus intervenciones sostuvieron que ellos continuaban manteniendo la representación socialista salida de España y que habían defendido la vigencia de su Gobierno, a pesar de los intentos por acabar con él. En aquel acto quedaron patentes las profundas diferencias discursivas existentes entre Negrín y sus seguidores socialistas, que afirmaban la necesidad de la unidad con los comunistas, posición especialmente marcada en la intervención del secretario general de la UGT, Rodríguez Vega. A diferencia de este, Negrín realizó un discurso mucho más moderado, centrado en defender la continuidad de las

(64) Quirosa-Cheyrouze y MuÑoz (2013): 613 y sig.

(65) «Información de la Agencia España» (México, 20 agosto 1945), AEM, A. Tomás Bilbao, Caja 2, Documentos personales 9: 1.

(66) «Nota de prensa conjunta difundida por la Agencia España» (27 de agosto de 1945), AEM, A. Tomás Bilbao, caja 2, documentos personales 8: 5-6.

(67) VV. AA. (1945). 
instituciones en el exilio y a combatir el desánimo de los españoles en el destierro. La denuncia a los intentos de articular una vía plebiscitaria contraria a la continuidad de las instituciones en el exilio, fue, sin duda, su eje central, alejado de la retórica revolucionaria y obrerista.

Negrín adoptó la decisión de mantener un perfil político de bajo perfil, para no perjudicar la actividad del Gobierno, aunque de forma discreta continuó realizando gestiones. Así, Julio Álvarez del Vayo informaba a Tomás Bilbao de la reunión de Negrín con Dean Acheson, subsecretario de Estado estadounidense y la solicitud de que reconociera al Gobierno republicano. Vayo se mostraba confiado de que a Negrín lo iban a imponer las circunstancias, «a pesar de los intentos de los republicanos por echarlo abajo» (68). Sus ministros continuaron manteniendo la fe en su proyección internacional y en su trabajo. Esa posición quedó recogida en febrero de 1946 en el «Proyecto de bases de resistencia española republicana». En ese documento planteaban la necesidad de la alianza de partidos para restablecer la Constitución de 1931, defender las instituciones, reforzar la política de resistencia y ayudar a los antifranquistas del interior (69). De nuevo el negrinismo perdía el apoyo del PCE que, desde la incorporación de Santiago Carrillo al Gobierno Giral, miraban de nuevo hacia otro lado.

Tomás Bilbao, en carta a Portela Valladares, confesaba que renovaba su apoyo a Negrín, aunque no se considerara negrinista y planteaba amargamente la hipocresía de los que trataron de acabar con la legalidad de su Gobierno y ahora se aferraban a él cuando lo habían conquistado (70). Bilbao consideraba que Negrín fue traicionado por Martínez Barrio, en el que había confiado plenamente hasta la consumación de los hechos, a los que Negrín se había resignado para evitar un desgaste mayor (71). A pesar de haber perdido el control del Gobierno en el exilio, los negrinistas continuaron trabajando por el mantenimiento de sus tesis, alarmados por la política dubitativa de José Giral y Fernando de los Ríos, y los intentos por parte de Trifón Gómez, desde dentro del Gobierno, e Indalecio Prieto, desde fuera, de acabar con su existencia. La negativa de Gran Bretaña y Estados Unidos a reconocer al Gobierno republicano en el exilio, instalado en París desde abril de 1946, y la existencia de maniobras realizadas en Londres por articular un Ejecutivo provisional con figuras como Gil Robles, Madariaga y Araquistain circulaban en el ambiente (72).

(68) Carta de Julio Álvarez del Vayo a Tomás Bilbao (New York, 21 de diciembre de 1945), AEM, A. Tomás Bilbao, Caja 1, correspondencia 2: 30.

(69) «Proyecto de bases de resistencia española republicana» (febrero 1946), AEM, A. Tomás Bilbao, caja 1, correspondencia 9: 5.

(70) Carta de Tomás Bilbao a Manuel Portela Valladares (México, 14 de enero de 1946), AEM, A. Tomás Bilbao, correspondencia 18: 19-23.

(71) Carta de Tomás Bilbao a Juan Carlos de Basterra (México, 19 de febrero de 1946), AEM, A. Tomás Bilbao, Caja 1, correspondencia 14: 1-7.

(72) Carta de Tomás Bilbao a Juan Carlos de Basterra (México, 9 de junio de 1946), AEM, A. Tomás Bilbao, Caja 1, correspondencia 14: 10-12. 
Ante el pesimismo reinante y la conciencia del agotamiento del liderazgo de Giral, Álvarez del Vayo planteaba la necesidad de sustituirlo por otro republicano, proponiendo el nombre de Portela Valladares, para estabilizar la situación, antes de que Negrín volviera a hacerse con las riendas del poder institucional. Negrín se mostraba cada vez más convencido de la irreversibilidad de la situación, manifestando un pesimismo que sus partidarios no compartían todavía (73). Su principal esperanza se situó en torno a las gestiones realizadas en la Asamblea General de las Naciones Unidas, donde Álvarez del Vayo trataba de contrarrestar el peso que en las diversas delegaciones ejercían los discursos de Prieto en contra del Gobierno republicano en el exilio (74).

Las tensiones dentro de la familia socialista permanecieron, debido a la apuesta de Prieto por el plebiscito y las maniobras desestabilizadoras de Trifón Gómez dentro del Gobierno Giral. Así, los socialistas negrinistas, apartados del gobierno y pronto expulsados en bloque del partido en abril de 1946, decisión ratificada en el II Congreso, celebrado en mayo, optaron por trabajar agrupados con otros partidarios de Negrín en España Combatiente, manteniendo también el Círculo Jaime Vera. Creado por Álvarez del Vayo, España Combatiente fue una asociación política que contó con el apoyo de los negrinistas dentro y fuera del PSOE, y consiguió sumar la firma del propio Negrín (75). A pesar de mostrar en su correspondencia privada sus críticas a la política seguida por Giral, el apoyo público al Gobierno republicano en el exilio continuó.

España Combatiente buscaba rehacer la unidad de acción de aquellos que todavía defendían la legalidad republicana. Las bases del proyecto fueron el restablecimiento de la república en España, sus instituciones y sus estatutos de autonomía, para lo que se fijaban tres ejes fundamentales. En primer lugar, la defensa internacional de la causa, en segundo lugar la resistencia contra el fascismo y por último el apoyo a los españoles antifranquistas del interior (76). Con un consejo directivo en París, controlado por Vayo y Velao, y secciones en los distintos países, en México la dirección recayó en Tomás Bilbao (77). Esta organización fue financiada por los contactos de Álvarez del Vayo entre los progresistas estadounidenses, sobre todo por el grupo de demócratas que editaban The Nation, publicación para la que el propio Vayo trabajaba como periodista (78).

(73) Carta de Julio Álvarez del Vayo a Tomás Bilbao (Los Ángeles, 24 de septiembre de 1946), AEM, A. Tomás Bilbao, Caja 1 correspondencia 2: 40-44.

(74) Carta de Julio Álvarez del Vayo a Tomás Bilbao (Nueva York, 26 de noviembre de 1946), AEM, A. Tomás Bilbao, Caja 1 correspondencia 2: 28-29.

(75) «Manifiesto de España Combatiente a los Republicanos españoles» (París, 19 de febrero de 1947), AEM, A. Tomás Bilbao, Caja 2, documentos personales 8: 1-2.

(76) «Bases de España Combatiente» (Paris, 19 de febrero de 1947), AEM, A. Tomás Bilbao, Caja 2, documentos personales 8: 7.

(77) Carta de Julio Álvarez del Vayo a Tomás Bilbao (París, 23 de marzo de 1947), AEM, A. Tomás Bilbao, Caja 1, correspondencia 2: 58.

(78) MARICHAL (1990): 67-72. 
A finales de los años cuarenta y principios de los cincuenta los acontecimientos internacionales y el establecimiento de una política de bloques de la Guerra Fría, marcó las preocupaciones de este grupo (79). Con el aumento del pesimismo de este núcleo por el progresivo reconocimiento recibido por el franquismo las tensiones en el grupo aumentaron. El núcleo en México, controlado por Tomás Bilbao y Segundo Blanco, se enfrentaba con Lamoneda y Álvarez del Vayo. Para los negrinistas no socialistas había que reconquistar el Gobierno republicano en el exilio, con Negrín al frente o sin él (80).

Negrín, por su parte, estaba cada vez más apartado de la política, aunque no retirado del todo. De hecho, los socialistas recibieron con cierto desagrado sus tres artículos en el New York Herald Tribune, en abril de 1948, mostrándose partidario de que España se beneficiase económicamente del Plan Marhsall, pero se aislase políticamente a la dictadura. Esta opinión causó desafecciones incluso entre sus allegados más incondicionales, como Ramón Lamoneda y Julio Álvarez del Vayo (81). A pesar de perder la fe en la propia figura de Negrín, siguieron manteniendo sus tesis de la continuidad de la legalidad republicana en el exilio. En julio de 1949, desde el Círculo Jaime Vera, se denunciaban los apoyos de los partidarios de Prieto al pretendiente don Juan de Borbón, acusándoles de haber desertado de los principios socialistas, y defendiendo la acción de España Combatiente como ariete político, sustento de las instituciones republicanas $(82)$.

Esta organización no tardó en tener fricciones ante la disyuntiva que se planteaba entre el apoyo incondicional que mostraban al Gobierno en el exilio y el profundo rechazo que les producía la política errática que sus diferentes responsables mantuvieron desde agosto de 1945. Tanto las tensiones en el seno de España Combatiente, como la necesidad de reactivar el socialismo, llevaron a la creación de la Unión Socialista Española, impulsada en 1951 por Álvarez del Vayo y Ramón Lamoneda, dejando caer la organización unitaria del negrinismo. La Unión Socialista Española nació siguiendo los mismos esquemas de la década anterior, con afán de integrar esta vez al mayor número de socialistas posibles, reafirmando la tradición obrerista y revolucionaria del socialismo español, abandonada por aquellos que decían ostentar la representación del partido de Pablo Iglesias. De nuevo se puso énfasis en la defensa de la legalidad republicana, así como se resaltaba la herencia marxista del socialismo español (83).

(79) «Boletín n 38 de España Combatiente sección México» (julio 1949), AEM, A. Tomás Bilbao, Caja 1, impresos sueltos 2: 22-25.

(80) Carta de Tomás Bilbao a Julio Álvarez del Vayo (México, 19 de febrero de 1951), AEM, A. Tomás Bilbao, Caja 1, correspondencia 13:41-42.

(81) MARICHAL (1990): 67 y sig.

(82) «A todos los republicanos españoles» manifiesto del Círculo Jaime Vera (México, 23 de julio de 1949) AEM, A. Tomás Bilbao, Caja 1, impresos sueltos 2: 21.

(83) «Unión Socialista Española, llamamiento» (octubre de 1951), FPI, A. Manuel Moreno Mateo, 474-12. 
Los intentos por parte del PCE en México de absorber los restos del negrinismo marcaron esos últimos tiempos (84). A pesar de los esfuerzos, ya sin el liderazgo claro de Negrín, el negrinismo socialista agonizaba en 1952, año en que desapareció su publicación, El Socialista (85). La Unión Socialista Española mantuvo por un tiempo más su voz crítica a los pactos firmados por los Estados Unidos con el franquismo en 1953 y en noviembre de 1956, coincidiendo con la muerte de Negrín, entonó el mea culpa ante la incapacidad de haber llegado a soluciones unitarias de los antifranquistas (86). Con la muerte de Negrín y la entrega de los papeles sobre el oro en la Unión Soviética a la España franquista, los negrinistas sufrieron otro duro golpe, el definitivo (87).

\section{CONCLUSIONES}

El negrinismo en el exilio mantuvo una intensa vida política y dio origen a discursos, publicaciones, proyectos políticos y espacios de sociabilidad mantenidos en torno a las expectativas de un retorno a España de la legalidad republicana según lo establecido en la Constitución de 1931 y sus instituciones. A pesar de su heterogeneidad y su dependencia de la figura del propio Negrín, consiguió establecer un discurso coherente y una línea de acción política definida, a lo largo de las dos décadas en las que las posibilidades de un retorno a España tuvieron mayor fuerza. Desde una perspectiva actual, gracias a la información que ahora conocemos, todo estaba perdido de antemano, por la actitud de las cancillerías aliadas, especialmente las británicas y las estadounidenses. Sin embargo, esto no era evidente en la época y no parece atinado reducir el significado de las actividades del exilio, a pesar de su eventual fracaso.

Desde sus orígenes, en el negrinismo convivieron dos tipos de seguidores diferentes, los socialistas y los no socialistas, siendo en muchas ocasiones los segundos, los más cercanos a la propia figura de Negrín. La confluencia del negrinismo socialista y el no socialista se dio en el terreno de la praxis política, en torno a la legitimidad del ejercicio de Negrín al frente del Gobierno.

El grupo funcionó como una red de confianza, construida en torno a la propia figura de Negrín. El negrinismo se produjo más por la congregación de grupos y que por la asimilación de discursos políticos uniformes. El grupo contó con un conjunto de valores compartidos en el tiempo, contó también con un mismo relato del pasado y con un proyecto de futuro para el restablecimiento

(84) «Carta del Círculo Cultural Jaime Vera a sus afiliados» (28 de octubre de 1951), FPI, A. Manuel Moreno Mateo, 474-2.

(85) PÉREZ GUERRERO (2008): 236.

(86) «Manifiesto contra el pacto yanquifranquista» (1 de octubre de 1953). FPI, A. Ramón Lamoneda, 171-26. Sobre el mea culpa, «Circular n. 4 de la Unión Socialista Española» (noviembre de 1956). FPI, A. Manuel Moreno Mateo. 474-12.

(87) ANsó (1976): 293-336. 
de la República en España. Existieron lazos y lealtades mutuas sostenidas hasta la desaparición física de Negrín. El negrinismo también dio lugar a espacios de sociabilidad compartidos, organizados en torno a un discurso sostenido durante lustros. No obstante, la procedencia diversa de los sectores políticos que se articularon en torno a Negrín es más que evidente. A pesar de compartir un proyecto en el exilio, el fin último no era el mismo. La visión sobre cómo debía ser la España del futuro no podía ser compartida por grupos originarios de imaginarios políticos asentados y en gran medida opuestos entre sí.

La retórica socialista y revolucionaria desempeñó un papel importante como aglutinante de una parte importante del negrinismo. La defensa del legado del Frente Popular permitió el mantenimiento de unas bases nada desdeñables de movilización política dentro del exilio, contando con núcleos representativos en México pero también en Francia. Mientras los grupos exiliados críticos hacia la gestión de los gobiernos de Negrín durante la Guerra realizaban la autocrítica sobre los acuerdos unitarios que dieron origen al triunfo electoral de febrero de 1936, los negrinistas de todo signo, defendían esa fórmula política que los había llevado al Gobierno. La mayoría de los sectores negrinistas no pertenecientes al PSOE adoptaron en sus discursos elementos de carácter socializante, defendiendo los orígenes populares de la República española. La defensa a ultranza de la voluntad popular, expresada libremente en las urnas, como la legitimidad por antonomasia, y reforzada por el sacrificio y la sangre de los españoles, fue un elemento esencial en su postura de resistencia dentro y fuera de España. A pesar de todo ello, el negrinismo fue algo más que solo parte de la gran familia socialista. La participación activa de republicanos, nacionalistas y cenetistas, así como el apoyo coyuntural e interesado del PCE, establecen un amplio abanico de posibilidades e interpretaciones de carácter ideológico y estratégico. En estas páginas hemos apuntado algo de esto.

Para finalizar, hay un factor importante que debemos tener en cuenta y sobre la que hemos insistido: la profunda desconexión que existió entre Negrín y las bases del negrinismo. En una primera fase, mientras sostuvo la representación del Gobierno hasta 1945, Negrín no hizo caso de la necesidad de implicarse activamente en la política partidista y la lucha que se estaba librando en México. Negrín estaba convencido de que aquellas pugnas eran insignificantes comparadas con las gestiones que él realizaba en Londres. Sin embargo, su inacción política le pasó factura a la hora de la reunión de las Cortes de 1945. Su descuido del ámbito doméstico de la política, pasó una importante factura frente a la crítica de sus enemigos. En México y en Londres se libraban batallas políticas diferentes y Negrín no fue consciente, como le señalaban sus seguidores, de lo importante que era no olvidar el frente mexicano.

Esa diferenciación entre Negrín y el negrinismo se acrecentó especialmente después de su salida del Gobierno en 1945. Su actitud discreta, su comportamiento libre y su modo personal de gestionar los asuntos, mostraron la clara diferencia entre él y sus partidarios. Si mientras mantuvo compromisos 
institucionales fue cauteloso, al estar liberado de ellos mostró un pensamiento libre e independiente en asuntos como el Plan Marshall o los documentos relativos al «oro de Moscú». Negrín fue un hombre que antepuso su sentido de Estado a los de partido, pagando un alto precio por ello. Incomprendido por casi todos, Negrín y el negrinismo representan dos sujetos históricos conectados, pero con elementos confrontados, sobre los que es necesario seguir profundizando en el futuro.

\section{BIBLIOGRAFÍA}

Alía Miranda, F. (2015). La agonía de la República. El final de la Guerra Civil española. Barcelona: Crítica.

Alpert, M. (1990). Don Juan Negrín en Londres 1940-1956. En J. Tusell, A. Alted, y A. Mateos, (eds.): La oposición al régimen de Franco (pp. 73-90). Madrid: UNED, Tomo I, vol. I.

Ansó, M. (1976). Yo fui ministro de Negrín, Barcelona: Planeta.

Azcárate, P. de (2010). En defensa de la República. Con Negrín en el exilio. Edición, estudio preliminar y notas de Ángel Viñas. Barcelona: Editorial Crítica.

Bahamonde, Á. (2014). Madrid 1939. La conjura del coronel Casado. Madrid: Cátedra.

Domínguez Aragonés, E. (1940). Los vencedores de Negrín. México: Ed. Nuestro Pueblo, Colección Independencia.

Fuentes, J. F. (2002). Luis Araquistain y el socialismo español en el exilio (1939-1959). Madrid: Biblioteca Nueva.

Gillespie, R. (1991). Historia del Partido Socialista Obrero Español. Madrid: Alianza.

Graham, H. (2005). El PSOE en la Guerra Civil, poder, crisis y derrota (1936-1939). Barcelona: Mondadori.

Heine, H. (1983). La oposición política al franquismo. Barcelona: Crítica.

Herrerín, Á. (2007). El dinero del exilio. Madrid: Siglo XXI.

Heywood, P. (1993). El marxismo y el fracaso del socialismo organizado en España, 1879-1936. Santander: Universidad de Cantabria.

Hoyos Puente, J. de (2012). La utopía del regreso. Proyectos de Estado y sueños de nación en el exilio republicano en México. México-Santander: El Colegio de México-Universidad de Cantabria.

Jackson, G. (2008). Juan Negrín. Barcelona: Crítica.

Juliá, S. (1997). Los socialistas en la política española, 1879-1982. Madrid: Taurus.

Lamoneda, R. (1942). «El Partido Socialista en la República Española». Discurso en el teatro de cinematografistas de México el 7 de junio de 1942. México: Biblioteca de «El Socialista».

Marichal, J. (1990). Juan Negrín y la continuidad de la II República. En J. Tusell, A. Alted y A. Mateos (eds.). La oposición al régimen de Franco (pp. 67-72). Madrid: UNED, Tomo I, vol. I. 
Mateos, A. (2002). Exilio y clandestinidad. La reconstrucción de UGT, 1939-1977. Madrid: UNED Ediciones.

- (2009). La batalla de México. Madrid: Alianza.

Miralles, R. (2003). Juan Negrín, la República en guerra. Madrid: Temas de hoy.

Moradiellos, E. (2006). Negrín, una biografía de la figura más difamada de la España del siglo xx. Barcelona: Península.

Negrín, J. (1941). «Discurso del Dr. Negrín». En VV. AA. Conmemoración del 19 de julio. Acto celebrado en Londres el día 20 de julio de 1941 en el Hogar Español (pp. 9-18), Londres: Publicación del Hogar Español.

Pérez Guerrero, J. C. (2008). La identidad del exilio republicano en México. Madrid: Fundación Universitaria Española.

Prieto, I. (1942). Confesiones y rectificaciones. México: Círculo Pablo Iglesias.

Quirosa-Cheyrouze y Muñoz, R. (2013). Gabriel Morón y Díaz. Trayectoria política de un socialista español. Almería: Editorial Universidad de Almería.

Sirvent Garriga, A. M. (2014). Rodolfo Llopis y el PSOE en el exilio. Madrid: UNO.

Tuñón de Lara, M., Miralles, R. y Díaz Chico, B. N. (1996). Juan Negrín López, El hombre necesario. Canarias: Gobierno de Canarias.

Velao, A. (1942). Pasado, presente y futuro. Discurso de 12 de julio de 1942. México: UDE.

Velázquez, A. (2014). Empresas y finanzas del exilio. Los organismos de ayuda a los republicanos españoles en México (1939-1949). México: El Colegio de México.

Viñas, Á. y Hernández Sánchez, F. (2009). El desplome de la República. Barcelona: Crítica.

VV. AA. (1945). «Por la República, contra el plebiscito». Texto íntegro del mitin del día 25 de noviembre de 1945, en el teatro de los cinematografistas. México: Biblioteca de «El Socialista».

Zugazagoitia, J. (1977). Guerra y vicisitudes de los españoles. Barcelona: Crítica. 
